\title{
Finite Element Analysis of the Balance Beam in Self-Handling Trailer
}

\author{
Jing-Tao YUE ${ }^{1, a^{*}}$, Li TANG ${ }^{1, b}$, Sun Dong ${ }^{1, c}$ \\ ${ }^{1}$ Military Transportation Institute, Tianjin, China \\ a20082008@vip.sian.com, bjjyjt@sina.com \\ ${ }^{*}$ Corresponding author
}

Keywords: Fea, Balance Beam, Self-Handling Trailer.

\begin{abstract}
Balance beam is the key component of the suspension of self-handling trailer. It is the walking balance mechanism of self-handling trailer and a part of the trailer to realize self-handling (the rear dump).Its reliability determines the reliability of the running and loading and unloading function of self-handling trailer. In order to determine the weak link and its degree, and to find a reasonable way to improve the structure and technology, this paper makes use of the relevant finite element analysis software to analyze the mechanics of the balance beam[1].
\end{abstract}

\section{Fault Description and Calculation Condition}

In the 10 thousands $\mathrm{km}$ reliability test, a total of two test vehicles have 8 cracks in the welding seam between rear balance beam and the upper arm around the connecting shaft of the outer sleeve. (Each car has two arms, and there is $5 \mathrm{~mm}$ circumferential fillet weld in the left and the right of the connecting shaft sleeve). As the trailer continues to run, the cracks continue to develop upward. Then the cracks develop along the both sides of the bending parts of the balance beam. Finally trailer's left rear wheel would tilt and can't run. During the reliability test, the fault occurs at the same time of the $8500 \mathrm{~km}$ mileage. After preliminary qualitative analysis, failure is caused by fatigue damage.

\section{Calculation and Analysis of the Original Vehicle Structure}

\section{Original Vehicle Structure Calculation}

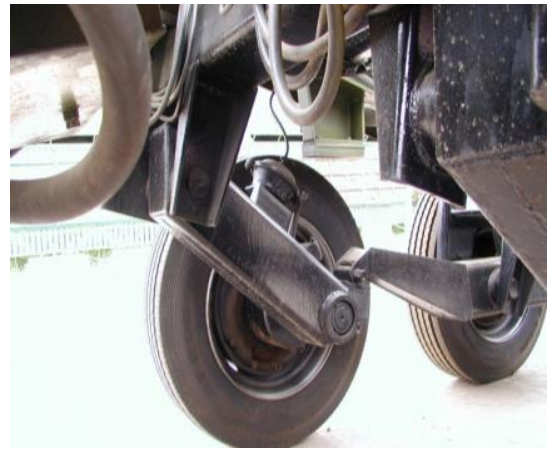

Fig. 1 Suspension system structure

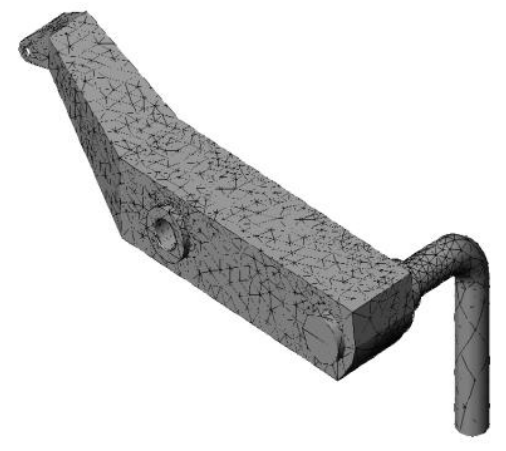

Fig 2 Balanced beam

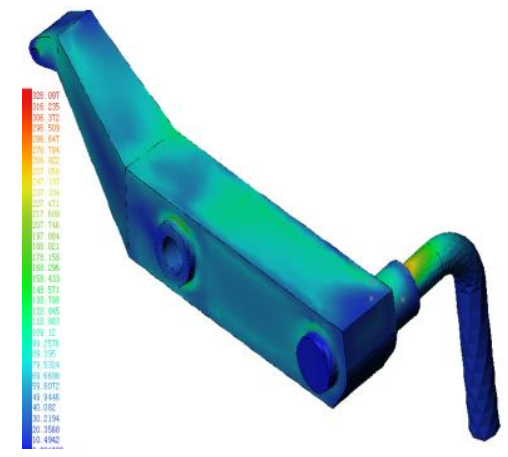

Fig 3 Stress analysis diagram

According to statistics, the limit speed of the off-road vehicle is determined by the root mean square (RMS) of vertical acceleration of the driver seat. This value is $0.7 \mathrm{~g}$. The passing rate of the suspension is about 2[2], so vertical acceleration RMS of the vehicle bridge is $1.4 \mathrm{~g}$. This trailer traveling condition is much better than the off-road vehicle. Taking into account the characteristic of trailer suspension, this paper take vertical acceleration RMS of the car body of 1.4 as the limit operating conditions and the whole vehicle load is calculated by $2.4 \mathrm{Mg}$. In addition, off-road vehicle dynamic load coefficient is about $5 \sim 6$, and the trailer adopts the dynamic load coefficient of 4 to carry out the strength check of the dynamic load. 


\section{Calculation of Force under Various Conditions}

Calculation results of force are shown in the following Tab. 1

Tab. 1 Calculation results of force under five kinds of working conditions

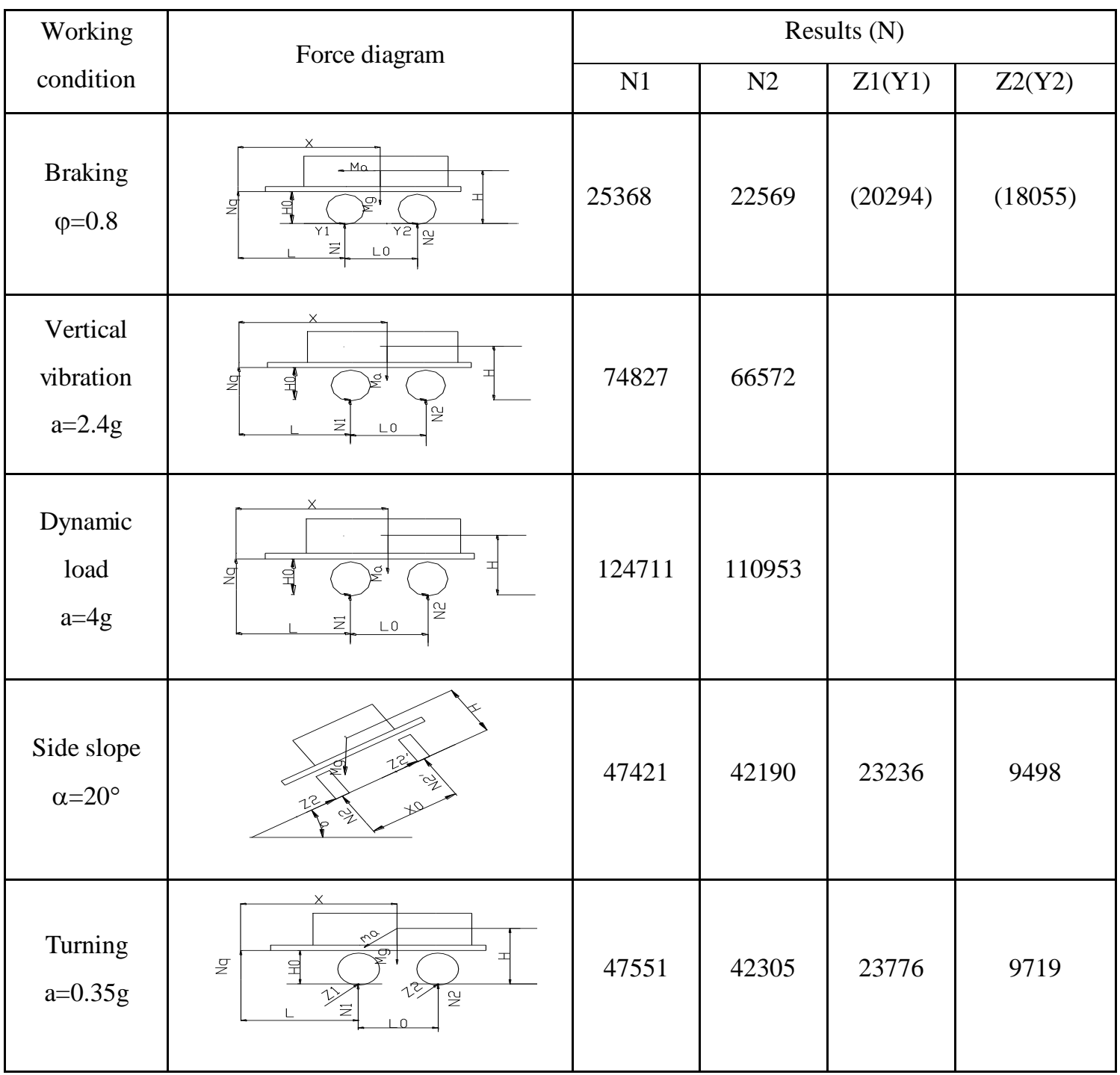

The maximum stress values of the middle hole in balance beam under various working conditions are shown in Tab. 2. In this paper, the material of the balance beam is $16 \mathrm{Mn}$, according to the design manual, its yield limit is $350 \mathrm{Mpa}$, and the allowable stress is $225 \mathrm{Mpa}(211-238 \mathrm{MPa})$

The maximum stress values of the area where the sleeve is setted under various working conditions are shown in Tab. 3.

\section{Analysis of Calculation Results}

a. It is clearance fit between the sleeve and the balance beam, and they are connected by the $5 \mathrm{~mm}$ height circumferential fillet weld (the height of the solid sample is less than $5 \mathrm{~mm}$ ). The stress should be basically similar to the condition of no sleeve when the welding between the sleeve and the balance beam has fallen. The dangerous condition is the vertical vibration condition, in this situation, the maximum stress value is about $850 \mathrm{MPa}$, and the allowable stress is $225 \mathrm{Mpa}$, which can not meet the requirements of the application.

b. The dangerous conditions (With sleeve) is vertical vibration condition, and in this situation the maximum stress value is $430 \mathrm{MPa}$ which still greater than the allowable stress values. If there is the interference fit or reliable welding between the sleeve and the balance beam, the situation is the same as 
above. As a result, the calculation shows that the whole structure strength is weak even if the trailer uses the interference fit or reliable welding.

c. From the calculation and analysis of the two models and five kinds of working conditions, it is clear that the vertical vibration condition is fault condition and is caused by the combination of bending and torsion. Therefore, the improvement of the structure should be based on strengthening bending resistance and twisting resistance.

\section{Calculation and Analysis of the Improved Structure}

\section{Improved Structure}

From the actual fault of the test, the 8 millimeters balanced beam has cracks and the welding between the sleeve and the balance beam has fallen. The 8 millimeters balanced beam only appeares the cracking weld. So the improvement of the balance beam structure is based on the balance beam with $10 \mathrm{~mm}$ thickness. In order to obtain a better structure, the following finite element analysis of the improved structure should be tested[3].

Basic structure: Section size (height * width * wall thickness) is $180 * 180 * 10 \mathrm{~mm}$. The improvement of heightening: Increase the height of the balance beam, section size is $200 * 180 * 10 \mathrm{~mm}$. The improvement of widening: Increase the width of the balance beam, section size is $180 * 200 * 10 \mathrm{~mm}$. The improvement of widening and heightening: Increase the width and height of the balance beam, section size is $200 * 200 * 10 \mathrm{~mm}$.Strengthening structure: In order to enhance the strength of the balance beam,this programme adds two reinforced plates on both sides of the layout of the area around the sleeve.

The improvement of heightening and strengthening: On the basis of the improvement of heightening, this programme adds two 10 millimeters reinforced plates on both sides of the area where the sleeve setted. The improvement of widening, heightening and strengthening: On the basis of the improvement of widening and heightening, this programme adds two 10 millimeters reinforced plates on both sides of the area where the sleeve setted. The diameter of sleeve is $110 \mathrm{~mm}$ (primary structure) and $130 \mathrm{~mm}$.

\section{Analysis of Calculation Results}

a. In the case of the constant section size, stress changes with the change of thickness of the balance beam. The result is as shown in Tab. 2 .

Tab. 2 The change of stress(thickness)

\begin{tabular}{|c|c|c|c|}
\hline Thickness (mm) & 8 & 10 & 12 \\
\hline Stress (Mpa) & 430 & 420 & 300 \\
\hline Allowable stress(Mpa) & & & \\
\hline
\end{tabular}

It can be seen that, with the increase of the wall thickness of the balance beam, the stress value decreases accordingly. However, only by changing the thickness to meet the strength requirements will increase quality of balance beam the and increase the processing difficulty, therefore, this paper selects the balance beam with a thickness of $10 \mathrm{~mm}$.

b. Stress changes with the change of the thickness and width of the balance beam.

As can be seen from the above table, with the increase of the height and width of the balance beam, the stress value decreases, but the change is small (only 20 30MPa). The stress changes greatly under the improvement of widening and heightening (up to $140 \mathrm{Mpa}$ ).

c. Stress changes with the change of the sleeve's diameter 
Tab. 3 The change of stress(Different sleeve diameter )

\begin{tabular}{|c|c|c|c|c|c|}
\hline Type & Basic structure & widening & $\begin{array}{c}\text { heighte } \\
\text { ning }\end{array}$ & $\begin{array}{c}\text { widening and } \\
\text { heightening }\end{array}$ & Strengthening \\
\hline Diameter 110mm & 420 & 400 & 390 & 280 & 200 \\
\hline Diameter 130mm & 310 & 300 & 280 & 175 & 170 \\
\hline Allowable stress(Mpa) & \multicolumn{5}{|c|}{225} \\
\hline
\end{tabular}

As can be seen from the Tab. 3, with the increases of the sleeve diameter, the stress decreased significantly (up to $90 \sim 130 \mathrm{MPa}$ ). Therefore, the sleeve's diameter should be determined as $130 \mathrm{~mm}$.

d. Stress change after the structure is strengthened (increasing the plate)

Tab. 4 The change of stress(Strengthening structure)

\begin{tabular}{|l|l|l|l|l|}
\hline Structure & Strengthening & Strengthening & Heightening & widening heightening \\
\hline Diameter (mm) & 110 & 130 & 130 & 135 \\
\hline Stress (Mpa) & 200 & 170 & \multicolumn{4}{|l|}{} \\
\hline Allowable stress(Mpa) & 225 & \multicolumn{4}{|l|}{} \\
\hline
\end{tabular}

As can be seen from the Tab. 4, the minimum stress corresponds to the improvement of heightening and strengthening. Therefore, in the next step to improve the structure, the improvement of heightening and strengthening is the preferred measures. However, it will make the process complicated.

d. Stress analysis on structure of the balance beam which can satisfy the strength condition.

From the above analysis, it can be seen that 7 types meet the strength condition of the balance beam structure. Structure with remarkable change of stress is the following three kinds:1improvement of widening and heightening; 2 strengthening structure 3 improvement of heightening and strengthening. In these three types of structures, the maximum stress change is under the improvement of heightening and strengthening,as can be seen from the Tab 5.

Tab. 5 Maximum stress value under various working conditions

\begin{tabular}{|c|c|c|c|c|c|c|}
\hline working conditions & Braking & $\begin{array}{c}\text { Vertical } \\
\text { vibration }\end{array}$ & Sideslip & $\begin{array}{c}\text { Side } \\
\text { slope }\end{array}$ & $\begin{array}{c}\text { Longitudi } \\
\text { nal slope }\end{array}$ & dynamic load \\
\hline $\begin{array}{c}\text { Maximum stress where } \\
\text { the sleeve is setted }\end{array}$ & 80 & 130 & 90 & 95 & 60 & 240 \\
\hline allowable stress & 225 & Yield limit & 350 \\
\hline
\end{tabular}

\section{Conclusion}

Calculation results are in accord with the actual fault conditions. A balance beam with the thickness of $10 \mathrm{~mm}$, the sleeve diameter of $130 \mathrm{~mm}$, the height of $200 \mathrm{~mm}$, the width of $180 \mathrm{~mm}$, and the reinforcing plate size of $180 * 180 * 10 \mathrm{~mm}$ is used; In order to improve the strength of the welding between the balance beam and the reinforced plate hole, this paper chamfers in it. The balance beam can greatly improve its fatigue strength by using shot-peening before and after welded. After taking the above structure, the calculated stress is $130 \mathrm{Mpa}$, the allowable stress is $225 \mathrm{Mpa}$, and the fatigue strength can be increased by $20 \%$ or more after shot peening treatment. 


\section{References}

[1] Ding Guoyu,He Xiaomin,Zhao Ziqiang,An Bokun,Song Yaoyu,Zhu Yixiao. Effect of dilution holes on the performance of a triple swirler combustor [J] Chinese Journal of Aeronautics. 2014 (06).

[2] ZHANC Xue-rong,Liu Xuejun,SU Qing zu. Testing validation and parameter optimization in occupant restraint system development [J].China Mechanical Engineering, 2008.19(10):1254-1257.

[3] Okubo Y.Akamatsu $\mathrm{T}$ Shirasawa K.mean Mean crushing strength of closed-hat section members[J].SAE Technical Paper 740040.Dearborn(MI):Society of Automotive Engineers, 1974. 